International Journal of Agriculture, Environment and Bioresearch

Vol. 4, No. 06; 2019

ISSN: $2456-8643$

\title{
PHYTOCHEMICAL SCREENING OF SOME SELECTED BANANA PEELS OF MUSA ACUMINATA SPECIE
}

\author{
Aina, O.O ${ }^{1}$, Oyedeji, M.B ${ }^{2}$, Adegboyega, D.A ${ }^{1}$, and Owoloja, A.O ${ }^{3}$ \\ ${ }^{1}$ Forest Conservation and Protection Department ,Forestry Research Institute of Nigeria, Ibadan \\ ${ }^{2}$ Vocational Studies Department, Federal College of Forestry, Ibadan. \\ ${ }^{3}$ Forest Product, Development and Utilization Department, Forestry Research Institute of Nigeria, Ibadan \\ http://doi.org/10.35410/IJAEB.2019.4460
}

\begin{abstract}
The study investigates the phytochemicals present in peels of selected banana species (Musa accuminata cv cavendish banana, Musa accuminata cv red skin banana, Musa accuminata cv white skin banana). The banana fruits used were bought at Apata market, Ibadan, and later peeled. The peels were air dried and subjected to extraction process using methanol maceration. The phytochemicals screened were tannin, flavnoid, saponin, oxalate, T. phenols, steroids, and terpenoid. The results showed that all phytochemicals screened were present in the peels at appropriate levels recorded (Oxalate ranges between $4.33-1.16$, tannin between $5.00-5.75$, flavonoid between $6.94-8.75$, steroid between $0.1-0.185$, terpenoid ranges between $0.21-$ 0.28 , T. phenol range between $53.35-82.20$ and saponin between $0.075-0.25$ ).
\end{abstract}

Keywords: Saponin, Phytochemicals, Banana, Peels.

\section{INTRODUCTION}

Bananas constitute the fourth most important global food commodity (after rice, wheat and maize) grown in more than 100 countries over a harvested area of approximately 10 million hectares, with an annual production of 88 million tionnes (Frison and Sharrock, 2001). The all year round fruiting habit of bananas put the crop in a superior position in bridging the "hunger gap' between crop harvests. It therefore contributes significantly to food and income security of people engaged in its production and trade, carbohydrate requirement for over 70 million people (IITA, 2002). Eastern and Southern Africa produces over 20 million tonnes of bananas which accounts for $25.58 \%$ of total world output (Karamura et al., 2006). The Great Lakes region covering parts of Uganda, Rwanda, Burundi, Tanzania, Kenya and DRC is the largest producer and consumer of bananas in Africa (Smale, 2006) where per capital consumption has been estimated at more than $250 \mathrm{~kg}$; the highest in the world (FAO, 2002).

All parts of the banana plant have medicinal applications (Amit and Shailandra, 2006): The cooked flowers are given to diabetics; the astringent plant sap in cases of hysteria, epilepsy, leprosy, fevers, hemorrhages, acute dysentery and diarrhea, and it is applied on hemorrhoids, insect and other stings and bites; young leaves are placed as poultices on burns and other skin afflictions; the astringent ashes of the unripe peel and of the leaves are taken in dysentery and diarrhea and used for treating malignant ulcers (Girish and Satish, 2008); the roots are 
administered in digestive disorders, dysentery and other ailments; banana seed mucilage is given in cases of diarrhea in India (Bhat et al., 2010).

Antifungal and antibiotic principles are found in the peel of fully ripe bananas (Brooks, 2008). The antibiotic acts against Mycobacteria (Omojasola and Jilani, 2009). A fungicide in the peel of green fruits is active against a fungus disease of tomato plants (Ponnuswamy et al., 2011).

Norepinephrine, dopamine, serotonin are also present in the ripe peel (Ratule et al., 2007). The first two elevate blood pressure; serotonin inhibits gastric secretion and stimulates the smooth muscle of the intestines (Anhwang et al., 2009).

Some of the specific diseases known to be cured by banana are Anaemia, High in iron: bananas are believed to stimulate the production of haemoglobin in the blood and also help in cases of anaemia (Amit and Shailandra, 2006). Blood Pressure: Banana is extremely high in potassium yet low in salt, making it the perfect food for helping to beat down blood pressure (Debabandya et al., 2010). Depression: This is because bananas contain tryptophan, a type of protein that the body converts into serotonin known to make you relax, improve your mood and generally make you feel happier (Girish and Satish, 2008).

Banana peels are widely used by smallholders as supplementary feeds for cattle and small ruminants in the tropics (Onwuka et al,. 2009; Emaga et al., 2011). There are nutritive values for ruminants are estimated to be similar to that of cassava peels or citrus. Green peels contain more metabolized than ripe peels. More research is needed into the value of the pods as feed as also the potential effect of the change in tannin content during ripening (Happ Emega et al,. 2011).

Although the use of peels of the fruit are not well recognized and its wider use can only be know through phytochemical analysis. Peels of some fruits are tightly stuck with other parts of the fruit while some are loosely peeled off when ripe. (Banana and Orange). Depending on the thickness and taste, fruit peel is basically an essential part for some. (Wiki, 2004)

Reports have shown that fruit and vegetable are sources of phytochemical thereby; discovery needs to be made on their potential even in some parts named as waste (peels). These natural secondary metabolites (phyto-nutrient) can inhibit the growth of pathogen or kill them and have at least toxicity effect (compare to the synthetic counterparts) to host cell that make them good alternatives to develop new antimicrobial medicine (Sheikhlar et al.,2013).

A large number of research studies have shown that a diet rich in antioxidant (vitamins) and other compound such as flavonoids is associated with improved health with lower risk in coronary disease and to prevent cancer. In addition to these antioxidants, and their function, improve the immune system. In other to determine the level of antioxidant or have knowledge of phytochemical present in certain food supply, there is need for research on such. The general term used for this is phytochemical or phytonutrient (Chung, 1998).

Phytochemicals are non-nutritive plant chemicals possessing varying degrees of diseasepreventive properties. They are invaluable sources of raw materials for both traditional and orthodox medicine. Phytochemicals may display their health protective effects in diverse ways. 
They can act as antioxidants and protect cells against free radical damage, e.g. polyphenols, carotenoids etc (Omoregiem and Osagie, 2012). They may also help in reducing risk for cancer by inhibiting tumor production (Devasagayam et al., 2004). Other modes of action are via antibacterial activity and hormonal stimulation (Mathew et al., 2012).

Phytochemical are plant derived chemicals, which are beneficial to human's health and disease prevention. In their primary state, plants, phytochemicals attract beneficial and repel harmful organism. Pythochemical like flavonoid functions as pathogen resistance (Agte,2000).

Phytochemicals are bioactive chemicals of plant origin. They are regarded as secondary metabolites because the plants that manufacture them may have little need for them. They are naturally synthesized in all parts of the plant body; bark, leaves, stem, root, flower, fruits, peel, seeds, etc. i.e. any part of the plant body may contain active components. T P. Tiwari, 2011.

The quantity and quality of phytochemicals present in plant parts may differ from one part to another. In fact, there is lack of information on the distribution of the biological activity in different plant parts essentially related to the difference in distribution of active compounds (or active principles) which are more frequent in some plant parts than in others .M. Lahlou,.., 2004.

Phytochemicals have been recognized as the basis for traditional herbal medicine practiced in the past ( Lalitha et al., 2012). In the search for phytochemicals that may be of benefit to the pharmaceutical industry, researchers sometimes follow leads provided by local healers in a region [D. K. Shrivastava, 2010]. Following such leads, plant parts are usually screened for phytochemicals that may be present. The presence of a phytochemical of interest may lead to its further isolation, purification and characterization. Then it can be used as the basis for a new pharmaceutical product.The general objective of this study is to screen the phytochemical in the peels of some selected varieties of banana and to compare the phytochemicals in the three selected species.

\section{MATERIALS AND METHOD}

\section{SAMPLES COLLECTION}

The fruit of the samples used are Musa acuminata cv cavendish banana, Musa acuminata $\mathrm{cv}$ red skin banana, and Musa acuminata cv white skin banana, were bought at Apata Market, Ibadan, Oyo state. The fruit were washed in clean water and dried with towel and after drying, the peels were carefully stripped off from the fruit. The stripped peels were then sun dried to reduce the moisture. After drying, the peels are packed in a container and carefully label to avoid misrepresentation during pounding into powdery form.

\section{Preparation Of Extracts}

The dried powder of each peel was subjected to maceration by $95 \%$ methanol in a $1 \mathrm{~L}$ capacity conical flask and dispensed in $900 \mathrm{ml}$ of distilled water. The mixture was stirred vigorously intermittently with a magnetic stirrer and then allowed to stand for $48 \mathrm{~h}$. It was stirred again and filtered through a Whatman filter paper lined funnel into a conical flask. The obtain extracts were 
Vol. 4, No. 06; 2019

ISSN: $2456-8643$

used for the phytochemical screening. (Harikrishnam et al., 2009) All extracts obtained were stored in a refrigerator until required for use.

\section{Phytochemical Analysis}

The extracts of Musa acuminata cv cavendish banana, Musa acuminata cv red skin banana, and Musa acuminata cv white skin banana peels were analysed for T.phenol, tannins, oxalate, steroids, flavonoids, saponins and terpenol using standard procedures.

\section{Test for Flavonoids}

This was determined according to the method of Harborne (1973). 2gram of the sample was boiled in $20 \mathrm{ml}$ of methanol, a chip of magnesium metal was served to the mixture and thereafter a few drops of $\mathrm{HCl}$ solution were added into it. The existence of a pink - red or orange colour displayed the presence of flavonoids (Harborne, 1998).

\section{Test for Oxalate}

1gram of the extracts was dissolved in $5 \mathrm{ml}$ of HCL (11\%) on steam bath. One milliliter of the filtrate was supplemented with few drops of Dragendoff's reagent. Greenish precipitate was considered as an indicator for the presence of oxalate. (Trease and Evans, 1989)

\section{Test for Saponins:}

Test of froth was used to indicate the presence of saponin. 5gram of the extract was treated with $15 \mathrm{ml}$ methanol. After evaporation, the residue was shaken strongly, with ethyl ether and $5 \mathrm{ml}$ of HCL. The formation of a stable emulsion indicated the presence of saponins (Trease and Evans, 1996)

\section{Test for Tannins:}

One gram of each extract made was dissolve in $10 \mathrm{ml}$ of distilled water and filtered a blue colour resulting from $\mathrm{FeCl} 3$ ferric chloride reagent to the filtrate indicated the presence of tannins in each exract. (Trease and Evans, 1996)

\section{Test for T. Phenols}

To determine the presence of T. phenol compound in extracts, 2gram of the extract was treated with $2 \mathrm{ml}$ ferric chloride. A deep blue or black color that appear was an indicator of phenols (Houghton and Raman, 1998).

\section{Test for Steroids}

Steroid content of the plant sample was determined using the method described by Trease and (Evans, 1996). A portion of $2 \mathrm{~mL}$ was taken from a solution of $2.5 \mathrm{~g}$ of powdered plant material prepared in $50 \mathrm{~mL}$ of distilled water after vigorous shaking for some minute. The extract solution was washed with $3 \mathrm{~mL}$ of $0.1 \mathrm{M} \mathrm{NaOH}(\mathrm{pH} 9)$ and later mixed with $2 \mathrm{~mL}$ of chloroform and 3 $\mathrm{mL}$ of ice-cold acetic anhydride followed by adding two drops of concentrated H2SO4 
cautiously. The absorbance of both sample and blank were measured spectrophotometrically at $420 \mathrm{~nm}$. A red colouration confirmed the presence of steroids

\section{Test for Terpenoids}

$1 \mathrm{ml}$ of chloroform was added to $2 \mathrm{ml}$ of each extract followed by a few drops of concentrated sulphuric acid. A reddish brown precipitate produced immediately indicated the presence of terpenoids. (Houghton and Raman, 1998)

\section{Statistical Analysis}

Homogenous sample of each of the peel of the Musa acuminata cv cavendish banana, Musa acuminata $c v$ red skin banana, and Musa acuminata cv white skin banana was subjected to phytochemical analysis for qualitative and quantitative determination of phytochemical (Sofowora, 1993). The quantitative date obtained was statistically analyzed using one way Analysis of Variance.

\section{Analysis Of Variance}

Analysis of Variance (ANOVA) was conducted to estimate the relative significance of various source of variation on T phenol, tannins, oxalate, steroids, flavonoids, saponins and terpenol.

\section{RESULT AND DISCUSSION}

Table 4.1: Phytochemical analysis of three Banana Fruit Peel

$\begin{array}{lccc}\text { Banana Species } & \text { Cavendish Peel } & \text { Red Skin Peel } & \text { White Skin Peel } \\ \text { Flavonoids } & ++ & +++ & +++ \\ \text { Saponin } & - & - & - \\ \text { Tannin } & + & + & + \\ \text { T.phenol } & +++ & +++ & + \\ \text { Oxalate } & - & - & + \\ \text { Steroid } & + & + & + \\ \text { Terpenoid } & + & + & +\end{array}$

All tests were carried out in triplicates.

KEY: +++ = Highly present; ++ = Moderate present; + = Less present; - = Absent 
Vol. 4, No. 06; 2019

ISSN: $2456-8643$

Flavonoids are known for their antioxidant and anti-inflammatory health benefits as the support of cardiovascular and nervous system. ( Hollmam, 1997 and Kumar, 1991). Cavendish banana contain anthocynins which belong to the parent class of molecules called flavonoids. Based on this, the laboratory research as well as studies in animals and humans suggested that anthocyanins may play important roles in helping reduced the risk of cardiovascular disease (CVD), cognitive decline and cancer. Wallace T.C (2011). Some plant saponins (e.g. from oat and spinach) may enhance nutrient absorption and aid in animal diggestion. However saponins are often bitter to taste, and so can reduce plant palatability (e,g.., In livestock feeds) or even imbue them with life threatening animals toxicity. Foerster, Hartmut (2006). The saponin content of the peel meals were observed to be absent which was reported by Kumar (1991) to be responsible for cattle losses when they grazed on Drymaria acrenaroides (alfonibrilla) and thus may not be hazardous to livestock. Oxalate, in the body, oxalic acid combine with divalent metallic cations such as calcium and iron to form crystals of the corresponding oxalates which are then excreted in urine as minute crystals. These oxalates can form larger kidney stones that can obstruct the kidney tubules. An estimated $80 \%$ of kidney stones are formed from calcium oxalate. Worcester (2005). At high concentrations, oxalate causes death in animals due to its corrosive effects (Kumar 1991). Those with kidney disorders, gout, rheumatoid arthritis, or certain of chronic vulvar pain (vulvodynia) are typically advised to avoid foods high in oxalic acid. Fretzdorff,B (2005).

Tannins compound are widely distributed in many species of plants, where they play a role in protection from predation, and perhaps also a pesticides, and in plant growth regulation. Katie E, Ferell.(2006). The astringency from the tannins is what causes the dry and pucker feeling in the mouth following the consumption of unripened fruit or red wine or tea. M.C Gee, Harold (2004). Recent studies have demonstrated that product containing chestnut tannins included at low dosages (0.15-0.22) in the diet of chickens may be beneficial. Schavone. et al., (March 2008). Barry (1987) opined that tannin if less than 2-3\% is beneficial for feeding ruminant animal.

Steroid is an organic compound with four rings arranged in a specific configuration. Example include the dilatory lipid cholesterol, the sex hormones estradiol and testosterone. Adolf Butenandt and Leopold Ruzicka (1939). Steroids have two principal biological function; certain steroid (such as cholesterol) are important component of cell membranes which alter membrane fluidity, and many steroids are signaling molecules which activate steroid hormone receptors.

Terpenoid are used extensively for their aromatic qualities and play a role in traditional herbal remedies. Terpenoids contribute to the scent of eucalyput, the flavors of cinnamon, cloves, and ginger, the yellow color in sunflowers, and the red color in tomatoes. Ayoola, GA (2008). The steroid and sterols in animals are biologically produced from terpenoid precursors. Sometimes terpenoid are added to protein, e.g,., to enhance their attachment to the cell membrane.

Many recent reports had shown that there is a direct relationship between total phenol content and the antioxidant activity in some food (Oboh, 2006), hence, could have antioxidant activity. In his work, Pieta (2000) reported that the phenolic compound are responsible for the most of the antioxidant in plant and these are packed in bra for maize and peels for banana all this are known as a waste. Oboh (2006) concluded that peels of banana are capable of causing various 
inhibitor of lipid peroxidation in liver, kidney and in tested cow's heart. Organically grown potatoes, orange and leaf vegetables have more phenolic compound and this may provide antioxidant protection against heart disease and cancer. Asami, Danny K. (2003).

Table 4.2: Quantitative analysis of phytochemical $(\mathrm{mg} / \mathrm{g})$ in three banana peels

\begin{tabular}{|lccccccc|}
\hline Samples & Flavonoid & Saponin & Terpenoid & Oxalate & Steroid & Tanin & T phenol \\
\hline T1 & $6.94 \pm 0.02$ & $0.25 \pm 0.01$ & $0.28 \pm 0.01$ & $2.75 \pm 0.25$ & $0.185 \pm$ & $5.60 \pm 0.02$ & $74.45 \pm$ \\
& & & & & 0.00 & & 0.95 \\
T2 & $8.75 \pm 0.11$ & $0.135 \pm$ & $0.23 \pm 0.00$ & $4.33 \pm 0.23$ & $0.175 \pm$ & $5.75 \pm 0.03$ & $82.20 \pm$ \\
& & 0.02 & & & 0.00 & & 0.10 \\
T3 & $8.53 \pm 0.04$ & $0.075 \pm$ & $0.21 \pm 0.00$ & $1.16 \pm 0.08$ & $0.10 \pm 0.01$ & $5.00 \pm 0.37$ & $53.35 \pm$ \\
& & 0.02 & & & & & 1.85 \\
GM & 8.07 & 0.153 & 0.24 & 2.75 & 0.15 & 5.28 & 70.00 \\
Fcal & 229.98 & 43.14 & 117.61 & 61.88 & 235.88 & 10.45 & 445.86 \\
LSD & 0.382 & 0.079 & 0.02 & 1.185 & 0.02 & 1.24 & 6.79 \\
CV $(\%)$ & 1.14 & 12.49 & 2.07 & 10.37 & 2.78 & 5.67 & 2.33 \\
\hline
\end{tabular}

Key: $\mathrm{T} 1=$ Cavendish Banana, $\mathrm{T} 2=$ Red Banana, $\mathrm{T} 3=$ White Banana

Oxalate was detected in banana peel meal and its concentration was between $1.16-4.33$. White skin banana has the lowest concentration which is 1.16. The concentration seems low compare with 100-900mg for sweet potatoes, cocoa powder, beets and spinach. At high concentration/ oxalate intake may be linked to the development of autism. Many of the food that contain oxalate are healthy foods that contain important antioxidants, fiber and other nutrient. At high concentration, oxalate causes death in animals and calcium oxalate stones.(Kumar, 1991)

Tannin range between 5.00 - 5.75 in banana peels. This is lower than 1-2mg commonly found in cereals and legumes reported to have depressed the growth rate, resulted in a poor feed efficiency ratio and increases the amount of food per unit weight gain in non-ruminants (Price and Bulter, 1980). Tannin negatively affect an animal's feed intake, feed digestibility, and efficiency of production.

Also, steroid range from $0.1-0.185$ in this sample analyzed. In a study, steroid in the body can act as hormones, and, therefore, their presence can impact a number of things from growth to sexual development. Adolf Butenandt (1939). Steroid such as cholesterol are important component of cell membranes which alter membrane fluidity. 
Flavonoid range between $6.94-8.75$ in the sample analyzed. In a study, in terms of their anticancer potential, research on flavonoids has been somewhat mixed. Due to their well documented antioxidant and anti-inflammatory properties, flavonoids would be expected to lower risk of certain cancers since chronic oxidative stress and chronic unwanted inflammation can place cells at greater risk of becoming cancerous.

Furthermore, terpenoid range between $0.21-0.28$ in banana fruit. This is observed to be low when compared with terpenoid content of $146 \mathrm{mg}$ and $353 \mathrm{mg}$ in maize, 206 and $280 \mathrm{mg}$ in shorgum, $14 \mathrm{mg}$ in potato (Concon, 1988), 624mg,855mg and $637 \mathrm{mg}$ in cassava, cocoyam and yam respectively (Marfo and Oke, 1988). Since it is low it is considered to be safe livestock consumption.

Quantitatively, Total phenol range between $53.35-82.20 \mathrm{mg} / \mathrm{g}$ in the sample. it is believed that phenol inhibit the growth of microbial organism when extracted with methanol after been tested on staphylococcus aureus (Gam-positive bacterial). (Sheikhlar, et al.,2013). They are also produced by plants and microorganisms, with variation between and within species.

Saponin level range from $0.075-0.25$ in the samples. In a research project, banana peel meals research were between 0.30 and 0.140 comparatively, the saponin level in is low and Kumar (1991) reported meals containing appreciably below $3 \mathrm{mg} \%$ is safe for livestock to feed on.

\section{CONCLUSION AND RECOMMENDATION}

Phytochemical screening test reveal the presence of Tannin, Saponin, Flavonoid, Oxalate, Terpenoid, Steroid, T.phenol in the extract of banana peels samples. Each of these phytochemocal is responsible for various protective and therapeutic effects. Phenol in proper level serves as erythrocyte membrane modifiers. The use of banana peels as food for animal supplement could be accountable for their uses and various antioxidants present in them which may be due to desirable presence of antioxidant properties molecules found in them. It was also observed that the concentration of these phytochemical were lower than the levels at which they are toxic to the body

\section{RECOMMENDATION}

Banana peels are major agricultural wastes which have been used as medicine, animal feeds, blacking of leathers (Hephburn and Blow, 2003; Wikipedia, 2007).

Banana peels are not poisonous. In fact, they're edible, and packed with nutrients. It contains high amounts of some vitamins, as well as magnesium and potassium, it also contain some fiber and protein. In the field of medicine, cavendish banana peel has been found to suppress testosterone-induced prostrate gland enlargement. Red skin banana are exceptionally high in antioxidants they also contain high content in some compounds that protect cells from the sort of mutations that lead to cancerous tumors. It is also help prevent red blood cells from breaking down. The peels of banana were found not to be toxic for human when use at appropriate level. The use of white skin banana according to research has proven countless studies to aid in lowering cholesterol. 
Vol. 4, No. 06; 2019

ISSN: $2456-8643$

The use of banana peels will reduce environmental pollution, cost incurred and full usage of natural nutrient found in them. In Nigeria, the use of banana peels can serve as source of employment and therefore, reducing the level of unemployment in our country. From the result obtained, it can be recommended for the quantification of various phytochemicals then isolation of characterization of pure compounds from the extracts for future studies.

\section{REFERENCES}

A. Brooks, (2008). Ethanol production potential of local yeast strains isolated from ripe banana peels, African J. Biotech., 7, $3749-3752$,.

Adolf Butenandt and Leopold Ruzika (1939): Isolation and structural studies of steroid sex.

Amit, R and S, Shailandra (2006). Ethnomedicinal approach in biological and chemical investigation of phytochemicals as antimicrobials. Indian Journal of Pharmaceutical Science 41: $1-13$.

B.A. Anhwange, T. J. Ugye and T. D. Nyiaatagher (2009), Chemical composition of Musa sapientum (banana) peels, Electronic J. Environ. Agric. Food Chern., 8, 437-442, 2009.

Bhat, M.S., Prabhakar, A., Rama, K. R. R., Madhu, G. M. and Rao, G. H. (2010). Statistical optimization and neural modeling of amylase production from banana peel using Bacillus subtilis MTCC 441. International Journal of Food Engineering 56: 34-45.

Chung, (1998): trend food science technology 4:168-175

Debabandya, M., Sabyasachi, M. and Namrata, S. (2010). Banana and its by-products utilization: An overview of Journal of Science and Industrial Research 69: 323-329.

Devasagayam,T.P.A .,Tilak, J.C .., Boloor, K.K.., Sane, K.S., Ghaskadbi, S.S. and Lele, R.D.(2004). Free radicals and antioxidants in human health: current status and futur prospects. JAPI. 52:794-804.

Forster; hartmut (22 may2006). Metacyc pathway: saponin biosynthesis" Retrieved 23 febuary 2009.

Girish, H.V and S.Satish (2008). Antibacterial activity of important medicinal plants on human pathogenic bacteria - a comparative analysis. World Application of Science Journal 5(3): 267271.

Happi Emaga, T., Bindelle, J.,Agneesens, R., Buldgen, A., Wathelet, B., Paquot, M. 2011, Ripening influences banana and plantain peels composition and energy content, Tropical animal health 43: 171-177

Harborne JB (1984). Phytochemical methods - a guide to modern techniques of plant analysis. 2nd ed. London: Chapman and Hall;, p. 4-16. 
Harborne JB. (1998) Phytochemical methods: methods; of extraction and Isolation. Chapman and hall, London, pp; 60-66.

Harikshinan, R., Balasundaran C., Kin M. C., Kim J. S., Han Y. J. and Heo, M, S., (2009):

Innate immune response and disease resistance in Carassius auratus b triherbal solvent extracts. Fish shellfish Immunol., 27:508-515.

Hollman, P.C.H., (1997): Bioavailability of flavonoids. European Journal of Clinical

Nutrition: 51:566-569.

Houghton, P. J. and Raman, A. (1998): Laboratory Handbook for Fractionation of Natural

Extracts Chapman and Hall, London, Page:199.

http :1 /www .nal. usda. gov/filic/foodcomp/ search/)

IITA (1998) Plantain and Banana Improvement Program-Annual Report for 1997.

International Institute of Tropical Agriculture, Onne, Nigeria,

P. Tiwari, B. Kumar, M. Kaur, G. Kaur, H. Kaur, Int. Pharm. Sciencia, 2011, 1, 98-106.

Karamura, D.A., Karamura, E. B. and Gold, C.S. (2006). Cultivar distribution in primary banana growing regions of Uganda. MUSAFRICA, 9:3-5.

Kumar, R. (1991): Antinutritional factors, the potential risks of toxicity and methods to alleviate them. Proceedings FAO Expert Consultation held at the Malaysian Agricultural Research and Development Institute, Kuala Lumpur, Malaysia.

Mathew, B., Jatawa, S. K. and Tiaari, A. (2012). Phytochemical analysis of Musa acuminata

CV cavendish banana and peel. International Journal of Pharmacy LRRD News. And Phamaceutical Science, 4(2): 269-371.

Mc Gee, Horold (2004). On food and cooking: the science and lore of the kitchen. New York: Scriner. P. 714. ISBN 0-684-80001 - 2.

Omojasola, P.F. and Jilani, O. P. (2009). Cellulose production by Trichoderma longi, Aspergillus niger and saccharomyces cerevisae cultured on plantain peel. ResearchJournal of Microbiology 40: 67-74.

Omoregei, E.S. and Osagie, A.U. (2012). Antioxidant properties of methanolic extracts of some Nigeria plants on Nutritionally- stressed rats. Nigerian journal of basic and applied science, 20(1): 7-20.Pharmacol., 34, 100- 110, 2002.

P. Tiwari, B. Kumar, M. Kaur, G. Kaur, H. Kaur, (2011). Int. Pharm. Sciencia, , 1, 98-106. 
Robinson, J.C. (1995) Systems of cultivation and management. In: Gowen, S.R. (ed.) Bananas and Plantains, pp.15-65. Chapman and Hall, London.

Smale, M. (2006) Assessing the impact of crop genetic improvement in sub-Saharan Africa: Research context and highlights. In: Melinda, S., Edmeades, S., and De Groote (Eds.). Promising Crop biotechnologies for smallholder farmers in East Africa: Bananas and Maize. Genetic Resources Policies Briefs 19-2006

Smale, M., De Groote, H., Falck-Zepeda (2006) Biosafety and biodiversity risks. In: Melinda, S., Edmeades, S., and De Groote (Eds.). Promising Crop biotechnologies for smallholder farmers in East Africa: Bananas and Maize. Genetic Resources Policies Briefs 26-2006

Sheikhlar A., A.R. Alimon, H. M. David, C. R. Sand and |H. Shanagi, (2013), Screening of

Musa acuminata CV cavendish banana Extracts for Antimicrobial Properties and Phytochemical Compounds. Journal of Biological Science 13:386-392.

Sofowora, A., (1993): Medicinal Plants and traditional medicines in Africa, John Wileyand sons, New York, pp: 97-145.

T. P. Lalitha, P. Jayanthi, (2012). Asian J. Plant Sci. Res., 2(2), 115-122.

Trease E. E. and W. C. Evans, (1989): A textbook of Pharmacognosy. $13^{\text {th }}$ Edn., Bailliere Tindall ltd., London, UK.

Wallace T.C., anthocyanins in cardiovascular disease. Adv Nutri. 2011;2:1-7. Wiki, (2004): a post on Wikipedia on nov ember 2004; nutritional value of peel. 